\title{
EDITORIAL
}

\section{Complete Mesocolic Excision-A Marker of Surgical Quality?}

\author{
Aisling M. Hogan • Des C. Winter \\ Received: 2 May 2009 /Accepted: 21 July 2009 / Published online: 5 August 2009 \\ (C) 2009 The Society for Surgery of the Alimentary Tract
}

Keywords Complete mesocolic excision · Colon cancer . Quality assurance

Quality assurance in surgery has never been more important. As public awareness and lay access to educational resources increase, the onus is on the surgical community to provide a consistently excellent standard of care. Nowhere is this more evident than the field of oncology. The establishment of the multidisciplinary care model ensures that patients are afforded timely and appropriate specialist referral, ${ }^{1}$ and an international vogue towards a patient-led service is evident in recent years. ${ }^{2}$ While involvement of chemo- and radiation-oncologists undoubtedly improves disease-free survival, there is an increasing body of evidence pointing to the primacy of surgical technique. ${ }^{3}$ Natural evolution of practice produced enhanced results, ${ }^{4}$ but a more active approach to establishment of guidelines and implementation of strict protocols has been adopted. ${ }^{5}$ The concept of variation in outcome dependent upon the individual surgeon performing the operation is not new ${ }^{6}$ but certainly adds weight to the argument for subspecialization in the light of the ongoing volume-outcome debate. ${ }^{7}$

Heald was first to describe total mesorectal excision, ${ }^{8}$ and while the technique may not have been entirely original, there is no doubt but that it has revolutionized the worldwide management of rectal cancer. ${ }^{9}$ It involves the formal resection of an intact tumor specimen with its full

A. M. Hogan $(\bowtie) \cdot$ D. C. Winter

Institute for Clinical Outcomes Research and Education (iCORE),

St. Vincent's University Hospital,

Elm Park,

Dublin 4, Ireland

e-mail: Aislinghogan@yahoo.com lymphatic drainage and blood supply within a predefined operative plane. However, until now, it has been difficult to attribute improvement in patient outcome specifically to technique alone, and the contribution of a concurrent global enhancement of rectal cancer care cannot be discounted. A recent study, however, succeeded in isolating adequate plane in rectal cancer surgery as an independent prognostic factor (irrespective of (neo)-adjuvant radiotherapy) and found it to be more important than resection margins, thus challenging traditional dogma. ${ }^{10}$ Short-course pre-operative radiotherapy combined with adequate plane surgery almost abolished recurrence at 3 years, thus allowing the consideration of rectal cancer as a curable entity. The authors describe a progressive improvement in technique (and thus outcome) over the study period and suggest that the process of executing the trial alone may have contributed to this. With modification of technique and standardization of adjuvant therapies, rectal cancer now demonstrates an equivalent, if not better, disease-free survival to stageequivalent colon cancer ${ }^{11}$ (whose management, until now, has been poorly standardized).

The relatively new concept of complete mesocolic excision in the management of colon cancer represents far more than evolution in operative technique. It attempts to extrapolate the advances in rectal cancer management and translate the vast survival advantage to colon cancer. This reflects the vogue towards quality assurance ${ }^{12}$ and international standardization of cancer care. While many guidelines govern the diagnosis of colon cancer, ${ }^{13}$ far fewer attempt to legislate for specifics of operative technique. Many surrogate markers for excellence in cancer management have been adopted. Number of lymph nodes resected has been endorsed to benchmark operative quality ${ }^{14}$ at certain disease stages $^{15}$ (with 12 considered adequate), ${ }^{16}$ 
and specialist trained surgeons are more likely to deliver this standard..$^{17}$ The impact of hospital volume on outcome following surgery for colon cancer ${ }^{18}$ is less certain than the convincing evidence pertaining to solid organ tumors, ${ }^{19}$ but the importance of the individual surgeon's demonstration of technical credentials has been consistently highlighted. ${ }^{20}$ Formal feedback from pathologists to surgeons regarding resection margins and planes of dissection is becoming the norm, ${ }^{21}$ and quality of histopathological reports has been improved by introduction of a standardized pro-forma. ${ }^{22}$ Clinical audit is well established as a professional requirement, ${ }^{23}$ and anonymous reporting in many jurisdictions allows for open and transparent analysis of outcomes. ${ }^{24}$ There is widespread awareness of the importance of opportunistic screening (colonoscopy ${ }^{25}$ or CT colonography ${ }^{26}$ ) resulting in diagnosis at far earlier disease stage. ${ }^{27}$

Although the idea of complete mesocolic excision is still embryonic, early results are encouraging. Only evidence from retrospective trials is available to date, but the potential survival advantage resulting from careful intact specimen dissection is undeniable. ${ }^{28}$ If nothing else, discrepancies in current practice have been highlighted, and the surgical community has been made aware that the time is ripe for formal standardization of operative practice. A recent study attributed improved cancer-free survival, reduced loco-regional recurrence, increased lymph node harvest, and decreased morbidity to the formal introduction of a clearly described operative technique for colonic resection. ${ }^{29}$ This involved separation of mesocolic and parietal planes and true central ligation of supplying arteries and draining vessels at their roots. While this could be considered nothing more than good oncological surgical practice, its widespread introduction as standard of care would undoubtedly translate to improved cancer-specific survival. Pathologists are in an ideal position to police the maintenance of high quality dissection, and their move toward subspecialization will certainly aid the optimization of the quality assurance process for colon cancer. ${ }^{30}$ Open communication and appraisal of technique in the forum of a regular multidisciplinary meeting provides an invaluable feedback opportunity for surgeons striving to optimize patient care.

Complete mesocolic excision is the latest addition to a plethora of surrogate markers for high quality care in operative management of colon cancer. Specifics of the technique are most likely less important than the generalized concept. It may, in fact, be its accompaniments (in the form of surgeon cognizance of anatomical planes, careful pathological evaluation, multidisciplinary communication) that afford survival benefit. However, it allows specific instructions to be issued to international surgeons involved in the operative management of colon cancer and, undoubtedly, has a valuable role to play in the overdue implementation of a quality assurance strategy in the management of colon cancer.

\section{References}

1. Segelman J, Singnomklao T, Hellborg H, Martling A. Differences in MDT assessment and treatment between patients with stage IV colon and rectal cancer. Colorectal Dis. 2009. In press. doi:10.1111/j.1463-1318.2008.01648.x

2. Sequist TD, Zaslavsky AM, Marshall R, Fletcher RH, Ayanian JZ. Patient and physician reminders to promote colorectal cancer screening: a randomized controlled trial. Arch Intern Med 2009;169(4):364-371. doi:10.1001/archinternmed.2008.564.

3. Morris M, Platell CF. Surgical volume influences survival in patients undergoing resections for stage II colon cancers. ANZ J Surg 2007;77(10):902-906. doi:10.1111/j.1445-2197.2007. 04270.x.

4. Pacelli F, Papa V, Rosa F, Tortorelli AP, Sanchez AM, Covino M, Bossola M, Doglietto GB. Four hundred consecutive total gastrectomies for gastric cancer: a single-institution experience. Arch Surg 2008;143(8):769-775. doi:10.1001/archsurg.143.8.769.

5. Kline RW, Smith AR, Coia LR, Owen JB, Hanlon A, Wallace M, Hanks G. Treatment planning for adenocarcinoma of the rectum and sigmoid: a patterns of care study. PCS Committee. Int J Radiat Oncol Biol Phys 1997;37(2):305-311.

6. Phillips RK, Hittinger R, Blesovsky L, Fry JS, Fielding LP. Local recurrence following 'curative' surgery for large bowel cancer: I. The overall picture. Br J Surg 1984;71(1):12-16. doi:10.1002/ bjs. 1800710104 .

7. Hollenbeck BK, Ji H, Ye Z, Birkmeyer JD. Misclassification of hospital volume with surveillance, epidemiology, and end results medicare data. Surg Innov 2007;14(3):192-198. doi:10.1177/ 1553350607307274 .

8. Heald RJ. The "Holy Plane" of rectal surgery. J R Soc Med 1988;81:503-508.

9. Wang C, Zhou ZG, Yu YY, Shu Y, Li Y, Yang L, Li L. Occurrence and prognostic value of circumferential resection margin involvement for patients with rectal cancer. Int J Colorectal Dis 2009;24 (4):385-390. doi:10.1007/s00384-008-0624-8.

10. Quirke P, Steele R, Monson J, Grieve R, Khanna S, Couture J, O'Callaghan C, Myint AS, Bessell E, Thompson LC, Parmar M, Stephens RJ, Sebag-Montefiore D, MRC CR07/NCIC-CTG CO16 Trial Investigators; NCRI Colorectal Cancer Study Group. Effect of the plane of surgery achieved on local recurrence in patients with operable rectal cancer: a prospective study using data from the MRC CR07 and NCIC-CTG CO16 randomised clinical trial. Lancet 2009;373(9666):821-828. doi:10.1016/S0140-6736(09) 60485-2.

11. Birgisson H, Talbäck M, Gunnarsson U, Påhlman L, Glimelius B. Improved survival in cancer of the colon and rectum in Sweden. Eur J Surg Oncol 2005;31(8):845-853. doi:10.1016/j. ejso.2005.05.002.

12. Kube R, Ptok H, Wolff S, Lippert H, Gastinger I, Study Group Colon/Rectum Carcinoma. (Primary Tumour). Quality of medical care in colorectal cancer in Germany. Onkologie 2009;32(12):25-29. doi:10.1159/000185572.

13. Rim SH, Seeff L, Ahmed F, King JB, Coughlin SS. Colorectal cancer incidence in the United States, 1999-2004: an updated analysis of data from the National Program of Cancer Registries and the Surveillance, Epidemiology, and End Results Program. Cancer 2009;115(9):1967-1976.

14. Baxter NN. Is lymph node count an ideal quality indicator for cancer care? J Surg Oncol 2009;99(4):265-268. 
15. Tsikitis VL, Larson DL, Wolff BG, Kennedy G, Diehl N, Qin R, Dozois EJ, Cima RR. Survival in stage III colon cancer is independent of the total number of lymph nodes retrieved. J Am Coll Surg 2009;208(1):42-47. doi:10.1016/j.jamcollsurg.2008.10.013.

16. Wright FC, Law $\mathrm{CH}$, Berry S, Smith AJ. Clinically important aspects of lymph node assessment in colon cancer. J Surg Oncol 2009;99(4):248-255.

17. Dillman RO, Aaron K, Heinemann FS, McClure SE. Identification of 12 or more lymph nodes in resected colon cancer specimens as an indicator of quality performance. Cancer 2009;115(9):1840-1848.

18. Rhoads KF, Ackerson LK, Jha AK, Dudley RA. Quality of colon cancer outcomes in hospitals with a high percentage of Medicaid patients. J Am Coll Surg 2008;207(2):197-204. doi:10.1016/j. jamcollsurg.2008.02.014.

19. Bilimoria KY, Talamonti MS, Sener SF, Bilimoria MM, Stewart AK, Winchester DP, Ko CY, Bentrem DJ. Effect of hospital volume on margin status after pancreaticoduodenectomy for cancer. J Am Coll Surg 2008;207(4):510-519. doi:10.1016/j. jamcollsurg.2008.04.033.

20. Larson DW, Marcello PW, Larach SW, Wexner SD, Park A, Marks J, Senagore AJ, Thorson AG, Young-Fadok TM, Green E, Sargent DJ, Nelson H. Surgeon volume does not predict outcomes in the setting of technical credentialing: results from a randomized trial in colon cancer. Ann Surg 2008;248(5):746-750. doi:10.1097/SLA.0b013e31818a157d.

21. den Dulk M, van de Velde CJ. Time to focus on the quality of colon-cancer surgery. Lancet Oncol 2008;9(9):815-817. doi:10.1016/S1470-2045(08)70216-X.

22. Siriwardana PN, Arunasalam P, Hewavisenthi J, Deen K. Histopathology Reporting in Colorectal Cancer (CRC): a proforma improves quality. Colorectal Dis. 2009. In press. doi:10.1111/ j.1463-1318.2008.01680.x

23. Hysong SJ. Meta-analysis: audit and feedback features impact effectiveness on care quality. Med Care 2009;47(3):356-363.

24. Ugolini G, Rosati G, Montroni I, Zanotti S, Manaresi A, Giampaolo L, Taffurelli M, Pricolo V. An easy-to-use solution for clinical audit in colorectal cancer surgery. Surgery 2009;145 (1):86-92. doi:10.1016/j.surg.2008.07.012.

25. Chao HH, Schwartz AR, Hersh J, Hunnibell L, Jackson GL, Provenzale DT, Schlosser J, Stapleton LM, Zullig LL, Rose MG. Improving colorectal cancer screening and care in the veterans affairs healthcare system. Clin Colorectal Cancer 2009;8(1):2228. doi:10.3816/CCC.2009.n.004.

26. Fraser-Hill M, Walsh C, Seppala R, Tao H, Stein L. Computed tomography colonography: the future of colon cancer screening. Can Assoc Radiol J 2008;59(4):191-196.

27. Maisonneuve P, Botteri E, Lowenfels AB. Screening and surveillance for the early detection of colorectal cancer and adenomatous polyps. Gastroenterology 2008;135(2):710. doi:10.1053/j.gastro.2008.04.039.

28. West NP, Morris EJ, Rotimi O, Cairns A, Finan PJ, Quirke P. Pathology grading of colon cancer surgical resection and its association with survival: a retrospective observational study. Lancet Oncol 2008;9(9):857-865. doi:10.1016/S1470-2045(08)70181-5.

29. Hohenberger W, Weber K, Matzel K, Papadopoulos T, Merkel S. Standardized surgery for colonic cancer: complete mesocolic excision and central ligation-technical notes and outcome. Colorectal Dis 2009;11(4):354-364

30. Washington MK. Colorectal carcinoma: selected issues in pathologic examination and staging and determination of prognostic factors. Arch Pathol Lab Med 2008;132(10):1600-607. 